УДК 159.9.072

DOI $10.17223 / 17267080 / 56 / 7$

\title{
А.О. Гетманенко
}

Московский государственный университет имени М.В. Ломоносова (Москва, Россия)

\section{Развитость креативного мышления в структуре музыкальной одаренности}

\begin{abstract}
Статья посвящена проблеме структуры детской музыкальной одаренности. Особое внимание уделяется креативности как одному из элементов музыкальной одаренности, представляющему ее творческий компонент. Дается характеристика наиболее эффективных методов диагностики креативности, а также приводятся данные авторского экспериментального исследования, организованного с использованием методик «Необычное использование» и «Завершение рисунка». Оиенивая результать диагностики, автор делает вывод о роли креативности в структуре детской музыкальной одаренности. Статья будет интересна педагогам, психологам, исследователям, сфера научных интересов которых лежит в области детской одаренности.
\end{abstract}

Ключевые слова: детская одаренность; музыкальная одаренность; креативность; структура одаренности.

\section{Актуальность проблемы детской музыкальной одаренности и ее структурных компонентов}

Проблема детской музыкальной одаренности является постоянным объектом исследований на протяжении уже многих лет. Особенно возрос интерес к данному вопросу в последнее время в связи с расширением детской аудитории, вовлеченной в освоение программ художественноэстетического цикла в учреждениях дополнительного образования детей по всей России. Отраженная в «Конценпции развития дополнительного образования» (2014) позиция, согласно которой необходимо расширить до $70 \%$ показатели вовлеченности подрастающего поколения в обучение по программам дополнительного образования, выделение предпрофессиональных и общеразвивающих дополнительных общеобразовательных программ обусловили необходимость более тщательного исследования творческой, и в частности музыкальной, одаренности с целью построения целостной и эффективной образовательной среды, способствующей выявлению, развитию и поддержке детской одаренности и воспитанию «взрослых» талантов.

При изучении проблемы детской музыкальной одаренности закономерно встает вопрос о ее структуре. Стоит отметить, что изначально музыкальная одаренность рассматривалась лишь как набор развитых специаль- 
ных способностей (таких как музыкальный слух, чувство ритма, гармонический слух и т.д.). Однако развитие исследовательской мысли привело к тому, что музыкальная одаренность, равно как и одаренность в принципе, стала рассматриваться как системно развивающаяся структура, включающая в себя ряд компонентов. Переходя непосредственно к вопросу о компонентном составе музыкальной одаренности, укажем на то, что сам феномен одаренности понимается нами как общесистемное свойство: «Она раскрывается как эмерджентное явление, как особое качество, которым не обладают его части, даже такие крупные части, как мозг, личность, субъект и т.д.» [1. С. 102].

\section{Подход и основания исследования}

Традиционно основой музыкальной одаренности считается музыкальность. Точка зрения, согласно которой музыкальность является ядром музыкальной одаренности, была впервые сформулирована Б.М. Тепловым. При этом сама музыкальность рассматривалась Б.М. Тепловым как «компонент музыкальной одаренности, который необходим для занятия именно музыкальной деятельностью в отличие от всякой другой и притом необходим для любого вида музыкальной деятельности» [2. С. 28] Выделяя в структуре музыкальности слуховой и эмоциональный компонент, исследователь, однако, утверждает, что именно способность «прочувствовать» и «переживать» музыку составляет ядро музыкальности. Особый интерес при изучении музыкальности и структуры музыкального таланта вызывает исследование Д.К. Кирнарской. Данная работа интересна тем, что в ней автор выделяет интонационный слух как способность, составляющую ядро музыкальности, давая этому понятию следующее определение: «Свойство психики, специально направленное на расшифровку музыкального смысла, на раскодирование коммуникативного намерения говорящего по отношению к слушателю-адресату исходя из совокупности ненотируемых свойств звукового целого, мы называем интонационным слухом» [3. С. 13] Таким образом, музыкальность рассматривается как некоторое качество психики, благодаря которому человек способен воспринимать транслируемую ему интонационнокодированную информацию и преобразовывать ее в систему образов, переживаний. Очевидно, что именно музыкальность представляет собой некоторый трансформатор, в котором происходит переработка семиотических музыкальных кодов. По мнению Д.К. Кирнарской, интонационный слух представляет собой наиболее распространенное качество, соответственно, только на основании наличия или отсутствия его у человека нельзя определить наличие или отсутствие одаренности. Следовательно, музыкальность будет рассматриваться нами как обязательный компонент структуры музыкальной одаренности, составляющий ее фундамент, но с необходимостью дополняемый и другими входящими в состав музыкальной одаренности компонентами. 
Вопрос о структуре музыкальной одаренности тесно связан с проблемой структуры одаренности как таковой. Зарекомендовали себя и подтвердили свою теоретическую и практическую значимость многофакторные модели одаренности. Традиция построения многофакторных моделей одаренности восходит к Дж. Рензулли, построившему ставшую наиболее популярной трехкольцевую модель одаренности, в соответствии с которой одаренность включает в себя такие компоненты, как:

- интеллектуальные способности выше среднего уровня;

- высокая креативность;

- высокая степень вовлеченности в действие.

Именно благодаря Дж. Рензулли в структуру одаренности был введен мотивационный аспект. Дальнейшие исследования психологии одаренности привели к модернизации модели одаренности Дж. Рензулли Ф. Монксом, который дополнил трехкольцевую модель введением факторов среды как основополагающих в формировании и развитии одаренности. Среди факторов среды особо были выделены Ф. Монксом семья, сверстники и школа.

Конкретизация проблемы структуры одаренности в отношении музыкальной одаренности обусловила появление аналогичных моделей, адаптированных в отношении музыкальной деятельности. Так, М.Т. Таллибулина [4] в структуру одаренности включает:

- общий компонент (невербальный интеллект, невербальная креативность);

- компонент музыкальных способностей;

- индивидуальный компонент (психологические свойства личности, нервная система, темперамент).

Вслед за Б.М. Тепловым С.Н. Лосева включает в структуру одаренности духовность, считая, что именно она «предопределяет перспективу развития музыкальной одаренности, так как значительным музыкантом может быть только человек с большим духовным - интеллектуальным и эмоциональным - содержанием» [5. С. 9].

Таким образом, очевидно, что в структуре музыкальной одаренности обязательным компонентом являются личностные особенности человека. Действительно, искусство обращается прежде всего к внутреннему миру человека, к его чувствам и переживаниям. Сами произведения искусства несут отпечаток личности своего создателя. Человек же, взаимодействующий с тем или иным видом искусства, невольно тоже становится его творцом. При этом акт его творчества выражается не в непосредственном создании произведения, но в его интерпретации, внутреннем преобразовании и формировании на его основе мнения, точки зрения, взгляда.

В этой связи необходимо рассмотреть исполнительство как один из видов музыкальной деятельности. Бесспорно, исполнение произведения является творческим актом. Исполнительская деятельность подразумевает способность к тонкому «прочувствованию» образов произведений, развитый музыкальный слух и вкус, способность слышать и чувствовать нюан- 
сы, а также воплощать желаемое и воспринимаемое в собственной деятельности. Очевидно, что процесс исполнения непосредственно связан с личностью человека, а также степенью развития его способностей: «Этическая ценность музыки зависит не от техники музыканта, а исключительно от его моральной направленности. Учащийся не должен никогда пытаться ослепить своего слушателя чисто техническим блеском; нужно стараться радовать его сердце, возвышать его чувства и ощущения, донося до его сознания благородные музыкальные мысли» [6. С. 96].

\section{Роль креативности в развитии музыкального таланта и ее выражсение в музыкально-исполнительской деятельности}

Исполнительская деятельность музыканта неоднородна по своей природе. Г.Л. Ержемский (1988) выделяет в ней два компонента: внутренний творческий акт и внешний процесс творческой реализации. Внутренний творческий акт связан с поиском исполнительского решения, интерпретацией образа, его преобразованием и дополнением. Внешний акт выражается в способности воплотить задуманное, использовать все необходимые исполнительские технические навыки для того, чтобы суметь донести возникший «внутренний» образ до зрителя. Таким образом, в ходе работы над произведением исполнитель выступает в роли проводника, интерпретатора, что особенно подчеркивает факт возникновения в ходе творческого осмысления «озарения», «инсайта», «вдохновения» - особого психологического состояния, в ходе которого человек внезапно обнаруживает решение, новый подход, новый способ.

Стоит отметить, что творческая деятельность зачастую является подконтрольной не рациональному сознанию человека, а интуиции. Позволим себе в данном ключе обратиться к предложенной Д.В. Ушаковым трактовке роли интуиции в акте творчества как способности передавать «дух» произведения, т.е. «смысл», состоящий не в теории или совокупности суждений о действительности [7].

Таким образом, в музыкально-исполнительской деятельности особенно выделяется роль креативности как способности нестандартно, неординарно мыслить, находить новые, неизвестные ранее способы решения. Примечательно, что соотношению общих и специальных компонентов в структуре музыкальной одаренности посвящено исследование М.А. Кононенко. Ею была установлена связь между развитием креативности и проявлением музыкально-исполнительских способностей, а также подчеркнута роль оригинальности и гибкости как важнейших показателей креативности [8].

Мы бы хотели также подчеркнуть роль креативности и музыкальности в структуре музыкальной одаренности. Более того, на наш взгляд, эти компоненты музыкальной одаренности неразрывно связаны. Музыкальность представляется как способность переживать, прочувствовать образ исполняемого произведения, накапливать эмоционально-образный багаж. Само восприятие музыки, как уже говорилось выше, связано с перекодированием 
информации, а следовательно, с интерпретацией. Возможность же интерпретации связана с творческим мышлением. Именно креативность (творческое мышление) обусловливает способность музыканта трансформировать музыкальные образы, находить новые смыслы. Музыкальность и креативность в структуре музыкальной одаренности тесно переплетаются и взаимодействуют друг другом. Музыкальность позволяет в полной мере воспринимать музыку, накапливая определенный творческий багаж. Этот багаж состоит не просто из образов, а из интерпретаций. При дальнейшем контакте с музыкой в ходе исполнительской деятельности человек актуализирует накопленные интерпретации, внося новый, личностный компонент в музыкальное произведение. Таким образом, именно развитая креативность обусловливает способность музыканта выражать образ исполняемого произведения, находить новые пути его исполнения, применения средств музыкальной выразительности.

Возвращаясь к вопросу о структуре музыкальной одаренности, мы бы хотели представить модель музыкальной одаренности, включающую следующие компоненты:

- музыкальность и творческое мышление (основа);

- специальные способности (в числе которых особое значение имеют чувство ритма, музыкальный слух, а на примере вокальной одаренности - чистое интонирование, вокальный слух, широкий динамический и вокальный диапазон);

- мотивационный компонент (включающий в себя внутренние мотивы и среду как фактор внешней мотивации);

- личностный компонент (тесно взаимосвязанный с самим ядром музыкальности по причине того, что степень развития личностных качеств оказывает влияние на восприятие человека и на творческий процесс как акт самоактуализации).

Мы бы хотели также сформулировать определение детской музыкальной одаренности как динамической, системно развивающейся в течение жизни ребенка структуры психики, являющейся показателем наличия потенциала для достижения высоких результатов в области музыкальной деятельности в целом и вокального исполнительства в частности. В данном определении мы опираемся на теорию динамического развития детского характера Л.С. Выготского, динамическую концепцию одаренности Ю.Д. Бабаевой, определение одаренности, сформулированное ведущими российскими психологами в «Рабочей концепции одаренности».

\section{Материалы и методики исследования}

\section{Диагностика детской музыкальной одаренности}

Подходя к вопросу диагностики музыкальной одаренности, целесообразно указать, что она должна носить системный и целостный характер. Учитывая также, что одаренность, согласно мнению Д.К. Кирнарской, 
представляет собой филогенетическую структуру, важно также указать на необходимость проведения лонгитюдного исследования одаренности, позволяющего отследить не только наличный уровень способностей, но и динамику их развития. В ходе диагностики оценка должна проводиться по каждому из компонентов, входящих в структуру одаренности, чтобы избежать ошибок в идентификации одаренности и присвоении «ярлыков одаренности». Более того, считаем важным указать на тот факт, что даже систематическое исследование одаренности не предотвращает возможности возникновения ошибочных выводов, поэтому, прежде чем определять наличие или отсутствие одаренности у человека, необходимо рассмотреть все его стороны, создать благоприятные условия, которые будут способствовать раскрытию индивидуального потенциала, дать возможность выразить и проявить себя.

Основываясь на мыслях, аналогичных вышеизложенным, в «Рабочей концепции одаренности» (2003) ведущими психологами высказывается мнение о том, что наиболее надежным и валидным методом диагностики одаренности является психолого-педагогический мониторинг.

Психолого-педагогический мониторинг - это континуальный процесс, включающий в себя систему взаимосвязанных методов и приемов, необходимых для оперативного отслеживания и анализа результатов деятельности, а также определения степени педагогических воздействий, воздействий среды учреждения на здоровье, физическое и психическое развитие ребенка, способствующий выявлению особенностей личности ребенка и являющийся основным ориентиром выбора методов обучения [9. С. 138].

Анализ наиболее популярных и исторически обосновавших свою надежность и эффективность методов, направленных на выявление одаренных детей, позволил нам сформировать собственную структуру психолого-педагогического мониторинга детской музыкальной одаренности, в состав которой вошли:

1. Тесты оценки креативности.

2. Метод «Певческая карта» [10] (оценка наличного уровня и динамики развития детских музыкальных способностей в области вокального исполнительства).

3. Анкетирование обучающихся (проводится после каждого отчетного мероприятия, участия в конкурсах с целью выявления психологического состояния обучающихся, их эмоциональных реакций).

4. Анкетирование родителей, учителей (оценка внешней мотивации).

5. Наблюдение за детьми в ходе занятий, ведение протоколов занятий, в которых отмечаются ключевые, знаковые моменты.

Подробнее остановимся на тестах оценки креативности. Как известно, понятие креативности тесно связано с таким термином, как «дивергентное мышление». Дивергентное мышление, наряду с конвергентным, было выделено Дж. Гилфордом как компонент структуры одаренности, благодаря чему была свергнута господствовавшая долгое время в науке точка зрения, согласно которой одаренность рассматривалась исключи- 
тельно как степень развития интеллекта. Выделив в структуре одаренности дивергентное мышление в качестве способности нестандартно мыслить, Дж. Гилфорд разработал также методику оценки креативности «Необычное использование». На основании оценки ответов детей по таким показателям, как гибкость, оригинальность и беглость, исследователю удавалось сделать вывод об уровне развития творческого мышления. Данная методика быстро обрела популярность и распространилась в образовательной среде.

Дальнейшее развитие проблема методов оценки креативности приобрела благодаря работам П. Торренса, в некоторой степени дополнившего и разработавшего методику Дж. Гилфорда. П. Торренсом были выделены четыре батареи тестов, направленных на оценку вербальной, изобразительной, звуковой и двигательной креативности. Примечательно, что М.Т. Таллибулина, разрабатывая диагностику детской музыкальной одаренности, особо указывала на то, что методика П. Торренса эффективна только в том случае, если используются тесты из каждой батареи. В случае, если будет пропущена оценка хотя бы одного вида креативности, невозможно будет сформировать целостное представление о степени развития творческого мышления, а следовательно, возможны ошибки и в оценке одаренности. Учитывая все вышесказанное, нами была сформирована батарея тестов, направленных на диагностику творческого компонента музыкальной одаренности, в которую вошли:

1) тест оценки вербальной креативности Дж. Гилфорда «Необычное использование»;

2) тесты оценки изобразительной креативности П. Торренса «Повторяющиеся фигуры» и «Завершение фигуры»;

3) карта оценки двигательной креативности;

4) карта оценки звуковой креативности.

Оценка результатов по всем вышеуказанным диагностикам проводилась на основе предложенных Дж. Гилфордом параметров креативности: гибкости, беглости и оригинальности.

Гибкость - способность интерпретировать, дополнять, модернизировать материал, тем самым осуществляя поиск новых подходов и путей решения, а в музыкальном исполнительстве - создавая необычный, неординарный образ.

Беглость - скорость порождения идей, способность быстро переключаться с одной идеи на другую (характеризует количество порождаемых образов и идей).

Оригинальность - способность продуцировать необычные, нестандартные идеи.

Оценка креативности также иногда проводится с привлечением дополнительных параметров, таких как разработанность (П. Торренс) и осмысленность (В. Шадриков). Однако, на наш взгляд, данные параметры допустимо не оценивать и не выделять, так как их значение напрямую связано с показателями охарактеризованных выше параметров - гибкости, оригинальности и беглости. 
Теперь более подробно остановимся на данных проведенных нами исследований, сконцентрировав внимание на результатах двух тестов из батареи оценки творческого мышления - теста П. Торренса «Завершение фигуры» и теста Дж. Гилфорда «Необычное использование».

\section{Результаты исследования и обсуждение}

В ходе исследования с использованием вышеуказанных методов была проведена оценка показателей креативности детей первого, второго, третьего и четвертого годов обучения, средний возраст - 10-13 лет (минимальный возраст - 7 лет, максимальный - 14 лет), осваивающих образовательную программу художественно-эстетической направленности (в комплекс изучаемых предметов входят «Актерское мастерство», «Танец», «Вокальный ансамбль»). Гендерный состав изучаемой группы: $20 \%$ мальчики, 80\% - девочки. Общее количество детей, участвовавших в исследовании, - 75 человек. Исследование проводилось в мае 2013 г.

Метод П. Торренса «Завершение рисунка» представляет собой батарею из 12 изображений, на которых в качестве стимульного материала присутствуют фрагменты рисунков (линии, фигуры). В ходе выполнения задания испытуемому предлагается подумать над тем, как можно дорисовать предложенные фигуры таким образом, чтобы создать целостный образ. Кроме того, в используемом нами варианте теста детям предлагалось также назвать рисунок, что позволило оценить не только изобразительную, но и вербальную одаренность обучающихся.

Время выполнения задания составляло 30 минут. Отметим, что все дети выполнили задание досрочно, несмотря на то, что у многих существовали пробелы в выполнении задания (оставались недорисованные фигуры). Тестирование проводилось в светлом, просторном помещении. Дети были рассажены таким образом, чтобы не иметь возможности видеть работы друг друга (что исключало «срисовывание» и копирование работ). Подчеркнем, что особую сложность вызвала необходимость придумать название рисунка. Как правило, названия носили констатирующий характер, кратко обозначая то, что изображено на рисунке («Дача» - в случае изображения деревенского домика, «Рыбка» - при изображении рыбы и т.п.). Зачастую также степень выраженности вербальной и изобразительной креативности разнились. Так, в тестовой тетради одной девочки (12 лет) были обнаружены рисунки, отличающиеся высокой степенью оригинальности и беглости, однако присваиваемые рисункам названия носили обыденный характер, порой даже не отражая полностью того, что изображалось. Перейдем к характеристике результатов тестирования по параметрам.

Беглость. Важно отметить, что практически все дети, принявшие участие в тестировании, набрали по показателю «Беглость» максимальный балл - 12 (исключение - девочка, 8 лет, беглость - 8). Высокий показатель беглости говорит о том, что все принявшие участие в тестировании дети с легкостью переключаются с одной идеи на другую. Однако изолированная 
оценка показателя беглости не позволяет оценить степень развития творческого мышления. Выраженная беглость может также свидетельствовать о высокой степени сосредоточенности ребенка, его стремлении скорее выполнить задание (в этом случае возможны различные варианты: выполнить быстрее как стремление к лидерству, желание быть первым и выполнить быстрее как желание скорее закончить тестирование, вызванное отсутствием заинтересованности).

Гибкость. Данный показатель оценивался в зависимости от того, как ребенок варьирует виды изображений. Все изображения условно подразделялись на «Живое» (изображение природы, животных, людей), «Материальное» (изображение различных предметов), «Видовое» (изображение картины, ситуации, действия), «Символьное» (абстрактные изображения, знаки, фоны и т.п.). Минимальный показатель по данному параметру составил 3 балла (т.е. тестируемый в ходе выполнения переключился с одного вида изображения на другой трижды). Важно отметить, что работа этого ребенка (девочка, 8 лет) характеризуется низкими показателями по всем параметрам. Показатель беглости составил 8, отсутствуют дополнения на многих рисунках. Сами дополнения носят элементарный характер. Низкий показатель гибкости обусловил также то, что ребенок, сконцентрировавшись только на одном виде изображения (например, на «Живом»), не имел возможности дополнить в соответствии с этим видом другие изображения, что отразилось на низком показателе беглости.

Средний уровень гибкости составил 6,4, что в целом характеризует степень гибкости как высокую. Максимальное значение гибкости - 9 баллов. Соглашаясь с мнением М.Т. Таллибулиной, отметим, что чрезвычайно высокий показатель гибкости отражает метание и неспособность соблюдать единую линию действий.

Оригинальность. При оценке оригинальности особое внимание обращалось на механизм дополнения рисунков. Учитывалось, работал ли ребенок с предложенными ему изображениями как с законченными формами, которые использовал как готовые и предзаданный элемент рисунка, или же дополнял предложенное изображение различными деталями, тем самым представляя его в качестве части какого-либо целого. Обращалось внимание также на то, стремился ли ребенок создавать целостное изображение, работая не только с неоконченной фигурой, но и оформляя пространство вокруг нее, или же процесс дорисовывания завершался в тот момент, когда придавалась законченная форма предложенному фрагменту.

Минимальная оценка оригинальности составила 17 баллов (у 6\% испытуемых). Рисунки этих детей носили условный характер дополнения. Как правило, завершение заключалось в повторении заданной фигуры, в результате чего создавался некоторый орнамент, состоящий из повторяющихся фигур.

Средняя оценка оригинальности составила 19,5 балла, что выражает достаточно высокий уровень оригинальности в структуре креативности. При этом в работах не наблюдалось стремления к вычурности, неординар- 
ности, граничащих с несуразностью и глупостью. Высокий показатель оригинальности достигался за счет того, что испытуемые вносили множество новых идей в изображение, что выражает стремление к созданию целостного, завершенного образа.

Максимальная оценка оригинальности составила 24 балла (у испытуемой девочки 12 лет). Важно при этом, что работа этой девочки отражала богатство внутреннего мира и образов, запечатленных в ее сознании, что находило свое воплощение в изображениях, носивших сказочный характер (например, изображалась не просто рыба, но с четко прорисованными чешуей, плавниками, исходящими изо рта пузырьками воздуха, с короной на голове).

Название. При оценке названия 0 баллов начислялось, если название отсутствовало; 1 балл - название есть, но носит констатирующий характер; 2 балла - развернутое название, образное, символичное. Минимальный балл по данному показателю составил 11 (девочка, 8 лет: ввиду отсутствия изображения отсутствовали и названия). Средний балл - 13,2, что в целом характеризует уровень развития вербальной креативности как достаточно высокий. Максимальный балл - 15 (у 12,5\% испытуемых).

Подводя итог оценке креативности по методике П. Торренса «Завершение рисунка», следует сказать, что данное тестирование позволило обратить внимание на тех детей, кто на занятиях не проявлял ярко выраженной творческой активности. Кроме того, нашла подтверждение гипотеза о том, что музыкальность и творческое мышление тесно связаны между собой. Дети, набравшие максимальное количество баллов в ходе проведения тестирования, отличались особой чувствительностью к музыке, что отмечалось педагогами на занятиях. Более того, поразившие своей оригинальностью и разработанностью рисунки девочки 12 лет подтвердили потенциальную возможность отнесения ее к категории музыкально одаренных детей: девочка на занятиях проявляла инициативу, часто можно было заметить, как она импровизирует под музыку, напевает сама себе, репетирует дома перед зеркалом. Также было обнаружено, что дети, получившие наиболее высокие баллы по тесту П. Торренса, получали и наиболее высокие оценки по методике «Певческая карта», что подтверждает мысль о том, что степень развития творческого мышления отражается на проявлении музыкальных способностей.

Однако, как было отмечено выше, эффективная оценка креативности исключительно в опоре на тестирование изолированного направления невозможна, в связи с чем нами было принято решение и о проведении тестирования по методике «Необычное использование» Дж. Гилфорда. Данное исследование проводилось на той же выборке детей, в тот же период времени. В ходе проведения тестирования детям было предложено подумать над тем, какие существуют нестандартные (но возможные) способы использования кирпича.

Наиболее распространенный ответ - использование в строительстве (его указали в перечне возможных вариантов все испытуемые). Среднее 
количество предлагаемых испытуемыми вариантов составило 4 (среди которых, как правило, были строительство, самооборона). 23\% мальчиков предложили вариант использования кирпича на занятиях боевыми искусствами (каратэ, единоборства). Максимальное количество вариантов было предложено девочкой 12 лет (8 вариантов), получившей максимальные баллы при оценке креативности по тесту П. Торренса. Среди предложенных ею оригинальных вариантов использования кирпича были: «Использовать в качестве гантелей», «Обложить дверь недругу», «Можно кирпичи коллекционировать», «Подкладывать под колеса, чтобы машина не укатилась». Данные ответы позволяют также оценить такие личностные качества ребенка, как тонкое чувство юмора, порой граничащее с сарказмом, наблюдательность (ответ об использовании для машины говорит о том, что ребенок обратил внимание на практическое применение кирпичей с этой целью).

\section{Заключение}

Проведенные тестирования дали возможность оценить уровень развития творческого мышления обучающихся по направлениям вербальной и изобразительной креативности. Так, тест П. Торренса позволил выделить детей, которые на занятиях не проявляли себя ярко, но при этом, судя по результатам тестирования, обладали высоким творческим потенциалом. Ориентация на потенциальный характер креативности многих современных детей вызвала необходимость разработки методик, способных оценить также двигательную и звуковую креативность.

Кроме того, нами было обнаружено, что результаты проведенных тестов взаимосвязаны с результатами оценки вокальных способностей детей по методике «Певческая карта». Данный факт позволяет сделать вывод, что развитое креативное мышление является необходимым компонентом в структуре музыкальной одаренности. Более того, обнаруживается связь творческого мышления с музыкальностью, выражаемая в способности воплощения музыкального образа произведения, его интерпретации, разработанности и оригинальности. Все вышесказанное позволяет рассмотреть музыкальную одаренность как комплексное качество психики человека, характеризующееся высокой степенью развития музыкальных способностей, в основе которого лежит степень развития творческого мышления и музыкальности. При этом обнаруживается тесная взаимосвязь творческого мышления и музыкальности, позволяющая судить о том, что в структуре музыкальной одаренности два этих качества составляют один творческий компонент.

\section{Лuтература}

1. Клочко B.E. Развитие одаренности в разных социокультурных и образовательных средах: проблемы организации кросс-культурного исследования // Сибирский психологический журнал. 2013. № 8. С. 100-110.

2. Теплов Б.М. Психология музыкальных способностей. М. : Наука, 2003. 379 с. 
3. Кирнарская Д.К. Теоретические основы и методы оценки музыкальной одаренности : автореф. дис. ... канд. психол. наук. СПб., 2006. 43 с.

4. Таллибулина M.T. Методы психологической диагностики музыкальной одаренности : методическое пособие. Пермь, 2008. 93 с.

5. Лосева С.Н. Возрастные и структурные особенности музыкальной одаренности учащихся и ее развитие в процессе вокально-хоровой деятельности : автореф. дис. ... канд. психол. наук. Иркутск, 2011. 20 с.

6. Петрушин В.И. Музыкальная психология. М. : Гаудеамус, 2009. 398 с.

7. Ушаков Д.В. Одаренность. Творчество. Интуиция // Современные теории одаренности / под ред. Д.Б. Богоявленской. М. : Молодая гвардия, 1998. С. 78-89.

8. Кононенко M.A. Соотношение общих и специальных компонентов в музыкальноисполнительской деятельности : автореф. дис. ... канд. психол. наук. М., 2004. 23 с.

9. Гетманенко А.О. Психолого-педагогический мониторинг как метод диагностики детской музыкальной одаренности // XVI Международная конференция, посвященная проблемам общественных и гуманитарных наук (культурология, религиоведение, искусствоведение, социологические науки, политологические науки). М. : Центр гуманитарных исследований «Социум», 2014. Ч. 3. С. 138-139.

10. Гетманенко А.О. Метод «Певческая карта»: характеристика и промежуточные результаты // Мир науки, культуры и образования. 2014. № 6 (49). С. 439-442.

Поступила в редакциюю 15.12.2014 г.; принята 21.04.2015 г.

Сведения об авторе:

ГЕТМАНЕНКО Анастасия Олеговна, аспирант кафедры музыкального искусства факультета искусств Московского государственного университета имени М.В. Ломоносова (Москва, Россия).

E-mail: ana2170@yandex.ru

Siberian journal of psychology, 2015, 56, 86-99. DOI 10.17223/17267080/56/7

Anastasia O. Getmanenko

Lomonosov Moscow State University (Moscow, Russian Federation).

E-mail:ana2170@yandex.ru

\section{Development of Creative Thinking in the Structure of Musical Aptitude}

The problem of children's musical aptitude has been a constant study subject for many years. The interest in this issue has significantly increased over the last time as a result of expansion of the children's audience involved in the familiarization with programs of the artistic and aesthetic cycle in the institutions of additional education for kids all over Russia. Handling the problem of children's musical aptitude, the question of its structure comes up. Musicality is usually considered to be the basis of musical aptitude. It is the quality of mentality thanks to which a person can acquire tonally coded information conveyed to him and change it into the system of images and feelings. Musicality is the transformer in which the semiotic musical codes are processed.

We would like to underline the correlation of creativity and musicality in the structure of musical aptitude. It is exactly the creativity (creative thinking) that causes the ability of a musician to transform musical images and to find new meanings. Thus, we have elaborated the model of musical aptitude that includes the following components: 
Musicality and creative thinking (basis);

Special abilities;

A motivational component;

A personal component.

Musical aptitude is thought as dynamic, systematically developing during a child's life structure of mentality that shows availability of a child's potential to achieve high results in the sphere of musical activity in general and vocal artistic performance in particular.

The testing of creativity carried out according to the methods of E.P. Torrance "Completion of a Drawing" and J.P. Guilford "Unusual Use" gave us a chance to estimate the development level of creative thinking of pupils in such directions as verbal and fine art creativity. For example, the test of E.P. Torrance helped us to single out children who didn't show their worth at the lessons, but had the high creative potential in accordance with the results of the testing. Orientation toward the potential character of creativity of plenty of modern children caused elaboration of the methods that could also estimate motor and sound creativity. Moreover, the connection of creative thinking with musicality was found out. It appeared in the ability of personification of a musical image of the piece, its interpretation, development and originality. All of the aforesaid make it possible to consider musical aptitude as a complex quality of the person's mentality that is characterized by the high development degree of the abilities for music based on the development degree of creative thinking and musicality. We find out close correlation of creative thinking and musicality at the same time. It allows us to conclude that these two qualities form one - the creative component - in the structure of musical aptitude.

Keywords: children's aptitude; musical aptitude; creativity; aptitude structure.

\section{References}

1. Klochko, V.E. (2013) Development of gifted in different socio-cultural and educational environments: organization of cross-cultural studies. Sibirskiy psikhologicheskiy zhurnalSiberian Journal of Psychology. 50 (4). pp. 100-110. (In Russian).

2. Teplov, B.M. (2003) Psikhologiya muzykal'nykh sposobnostey [The psychology of musical abilities]. Moscow: Nauka.

3. Kirnarskaya, D.K. (2006) Teoreticheskie osnovy i metody otsenki muzykal'noy odarennosti [Theoretical bases and methods of evaluation of musical talent]. Abstract of Psychology Doc. Diss. St. Petersburg: Saint-Petersburg State University.

4. Tallibulina, M.T. (2008) Metody psikhologicheskoy diagnostiki muzykal'noy odarennosti [Methods of psychological diagnosis musical talent]. Perm: Perm State Institute of Arts and Culture.

5. Loseva, S.N. (2011) Vozrastnye $i$ strukturnye osobennosti muzykal'noy odarennosti uchashchikhsya $i$ ee razvitie v protsesse vokal'no-khorovoy deyatel'nosti [Age and structural features of the musical talent of students and its development in the process of vocal and choral activities]. Abstract of Psychology Cand. Diss. Irkutsk: Irkutsk State Pedagogical College.

6. Petrushin, V.I. (2009) Muzykal'naya psikhologiya [Music psychology]. Moscow: Gaudeamus.

7. Ushakov, D.V. (1997) Odarennost', tvorchestvo, intuitsiya [Talent, creativity, intuition]. In: Bogoyavlenskaya, D.B. (ed.) Osnovnye sovremennye kontseptsii tvorchestva i odarennosti [The basic modern concepts of creativity and talent]. Moscow: Molodaya gvardiya. pp. 78-89.

8. Kononenko, M.A. (2004) Sootnoshenie obshchikh $i$ spetsial'nykh komponentov $v$ muzykal'no-ispolnitel'skoy deyatel'nosti [The ratio of general and specific components in 
the musical performance]. Abstract of Psychology Cand. Diss. Moscow: Institute of Psychology of the RAS.

9. Getmanenko, A.O. (2014) [Psycho-pedagogical monitoring as a method of diagnosis of children's musical talents]. XVI Mezhdunarodnaya konferentsiya, posvyashchennaya problemam obshchestvennykh i gumanitarnykh nauk (kul'turologiya, religiovedenie, iskusstvovedenie, sotsiologicheskie nauki, politologicheskie nauki) [The 16th International Conference on Social Sciences and Humanities (Cultural Studies, Religious Studies, Art History, Sociology of Science, Political Science]. Moscow: Humanities Research Center "Sotsium". pp. 138-139. (In Russian).

10. Getmanenko, A.O. (2014) About the identification methods of the development of children's musical abilities. Mir nauki, kul'tury i obrazovaniya. 6 (49). pp. 439-442. (In Russian).

Received 15.12.2014;

Acepted 21.04.2015 